\title{
Patellaplasty, as an Alternative to Replacing Patella in Total Knee Arthroplasty
}

\author{
Sanjay Agarwala, Anshul Sobti*, Siddhant Naik \\ Department of Orthoapedic Surgery, P.D Hinduja National Hospital \& Medical Research Centre, Mahim, \\ Mumbai, India \\ Email: drsa2011@gmail.com, ${ }^{*}$ anshulsobti@gmail.com, siddhant.naik@hotmail.com
}

Received 6 August 2015; accepted 5 September 2015; published 8 September 2015

Copyright @ 2015 by authors and Scientific Research Publishing Inc.

This work is licensed under the Creative Commons Attribution International License (CC BY).

http://creativecommons.org/licenses/by/4.0/

(c) (i) Open Access

\begin{abstract}
Aim: In tricompartmental osteoarthritis of the knee, the patellofemoral articulation is severely affected due to degenerative changes. Patellaplasty is done as a part of total knee arthroplasty in these cases to smoothen the articular surface of patella. However, an ideal technique with easy reproducibility has been scarcely reported for the same. Method: We describe a method of using electrocautery and power saw with thin blades for patellaplasty. Results: Using this technique, we have produced results, which are comparable with cases where patellar resurfacing has been done. Conclusion: This described method for patellaplasty is easy with good reproducibility.
\end{abstract}

\section{Keywords}

Patellaplasty, Electrocautery, Power Saw, Total Knee Arthroplasty

\section{Introduction}

There has been significant progress in surgical design and technique, which has led to improved function for patients after total knee arthroplasty (TKA). The modern implants have ensured that more than $90 \%$ of modern primary total knee replacements survive for at least fifteen years [1]. However, the problems related to the patellofemoral joint in unresurfaced patellae [2] such as progressive degenerative changes on the lateral facet occurred in $85 \%$ of patellae [3] [4], and the increased incidence of anterior knee pain [5] have not been eliminated. These lead to continued symptoms and reduced quality of life for the patient [6] [7].

To deal with the patellofemoral joint, two schools of thought have existed - patellar resurfacing wherein the native articular surface of the patella is replaced with poly and patellaplasty where the native articular surface is kept intact. When the decision is made not to resurface the patella, caution must be exercised to assure that the "Corresponding author. 
articular surface of the patella is smoothened and that the osteophytes are thoroughly excised. Various techniques are described in literature ranging from use of electocautery [8], bone nibblers, surgical knife, drills [9], facetectomy [10] etc. alone or in combination. We describe a technique for patellaplasty using electrocautery and power saw.

\section{Surgical Technique}

The same senior surgeon performed the procedure and the technique was the same in all cases. Suitable anaesthesia was administered and the procedure was performed under tourniquet. After ensuring all aseptic precautions, a midline patellar incision was made. The incision was deepened in layers till the fascia of quadriceps is reached. Arthrotomy was performed using the midvastus approach, and the vastus medialis was dissected through its substance. The patella was everted and held securely with the help of towel clip. A narrow Langenback's retractor was held on the superior aspect of the patella to protect the soft tissues (Figure 1).

Next, the peripatellar soft tissues were cauterized with the help of thermal electrocautery to denervate the patella and also to elevate the margins of patella for better demarcation (Figure 2).

The hypertrophied lateral facet, which was to be excised, was demarcated with the help of electrocautery. This also helped in preventing excessive resection of the lateral facet (Figure 3).

The hypertrophied facet was excised with the help of power saw. The Lagenback's retractor was used to protect the quadriceps tendon from lacerations due to the power saw. The femoral condyles were also protected from the power saw with the help of a periosteum elevator (Figure 4).

Similarly, the osteophytes over the superior, inferior and lateral borders of patella were excised in order to create a uniform margin (Figure 5). Next, the articular surface of the patella was smoothened using a power saw. This ensured the articular surface of the patella did not cause abrasive wear over the implants (Figure 6). The finesse of the articular surface was confirmed by placing a finger on it. If it feels rough, it is further smoothened with the help of saw (Figure 7).

\section{Discussion}

In total knee arthroplasty for tricompartmental osteoarthritis of the knee, resurfacing of the patella has remained

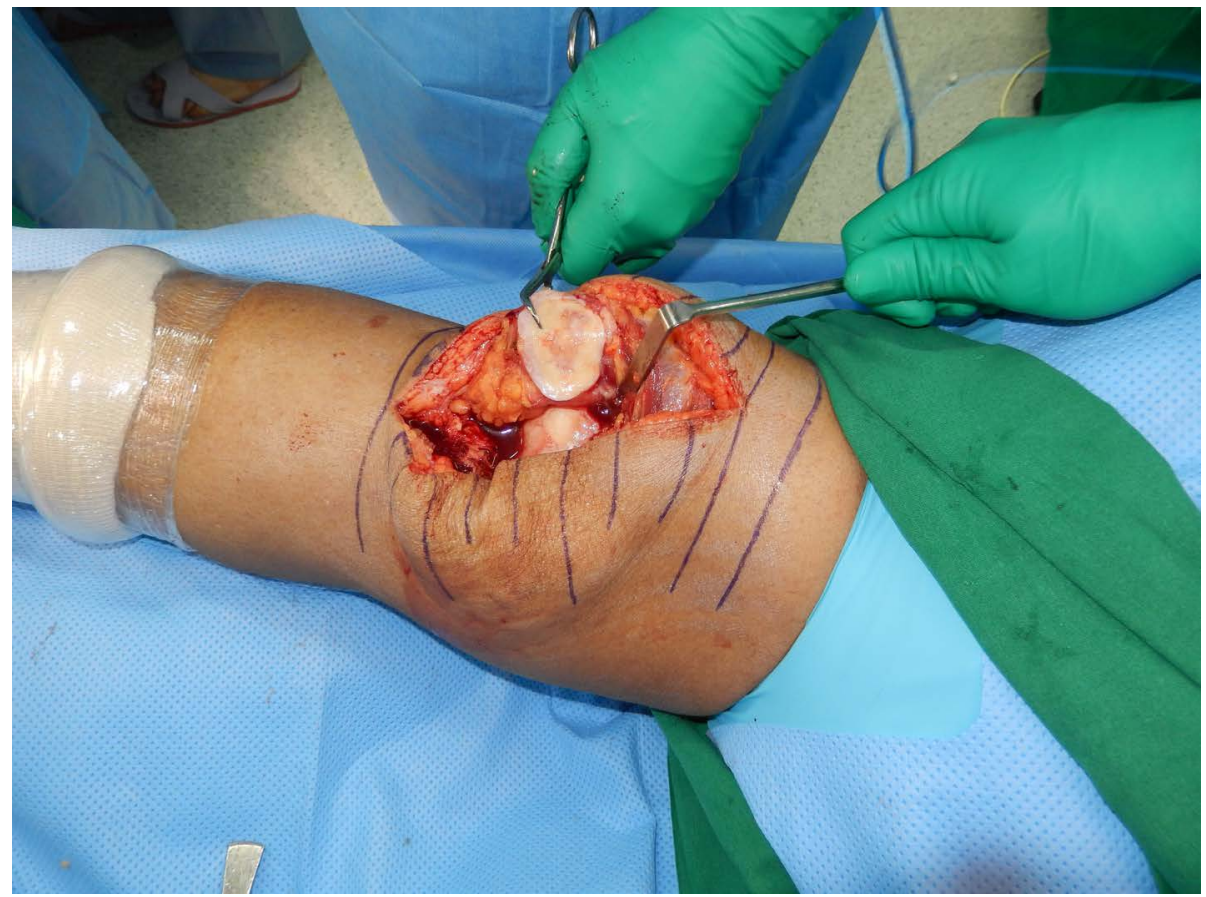

Figure 1. Patella everted with towel clip, Langenback's retractor held on the superior aspect of the patella to protect soft tissues. 


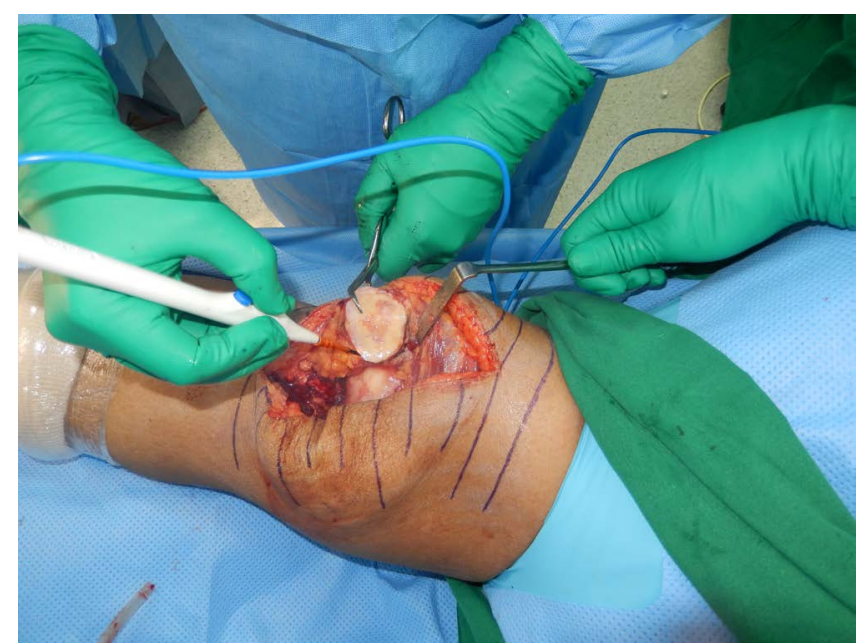

Figure 2. Peri-patellar soft tissues cauterized with the help of thermal electrocautery to denervate for better demarcation.

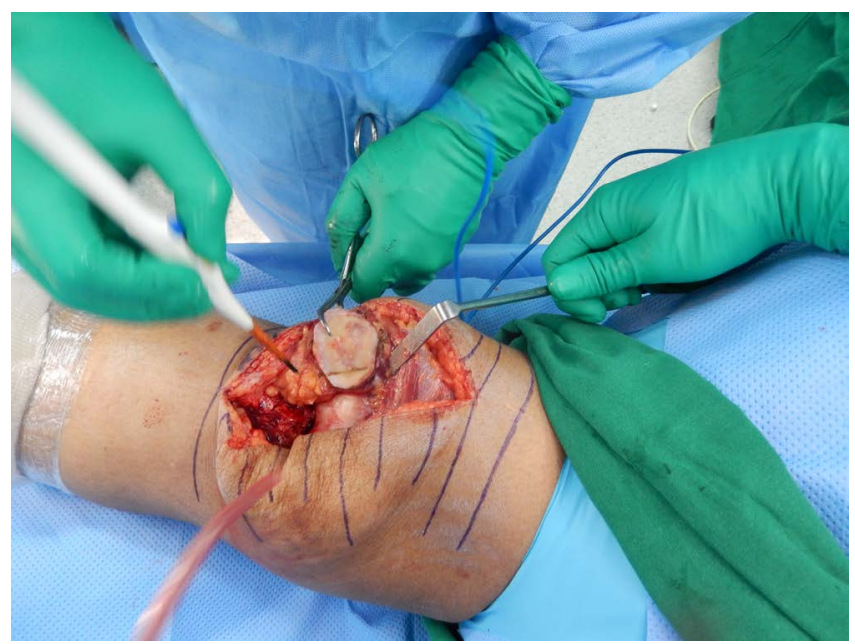

Figure 3. The hypertrophied lateral facet, demarcated with the help of electrocautery.

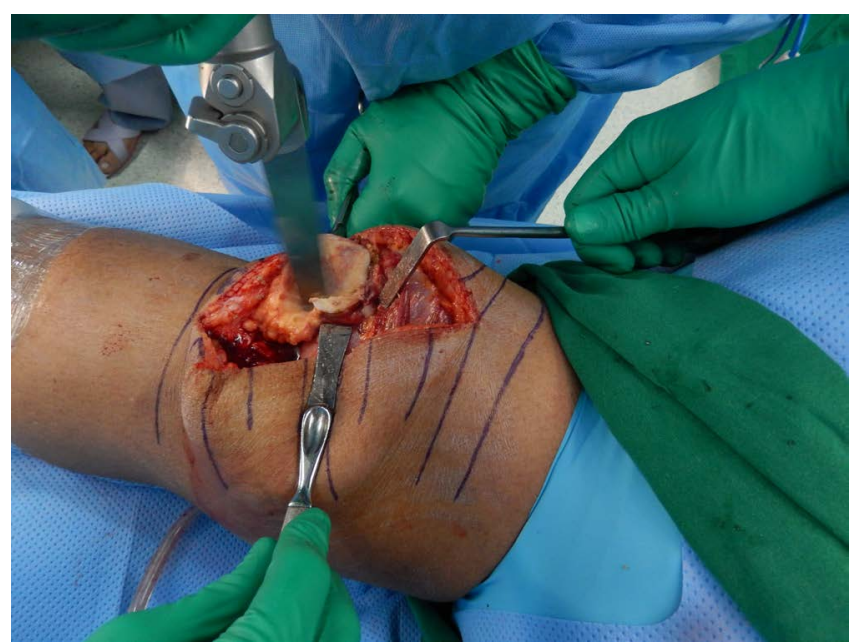

Figure 4. Femoral condyles protected with the help of a periosteum elevator. 


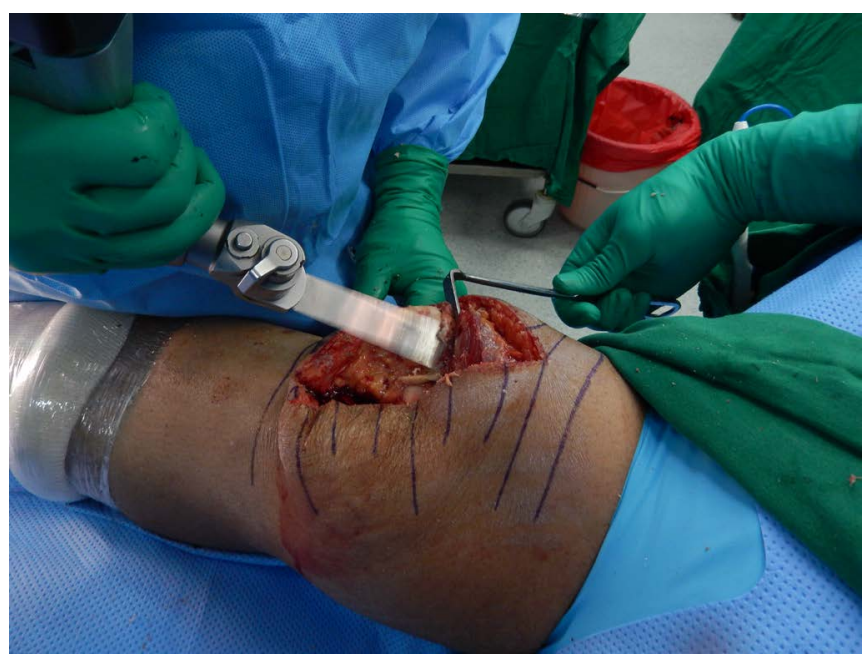

Figure 5. Osteophytes over the superior, inferior and lateral borders of patella were excised.

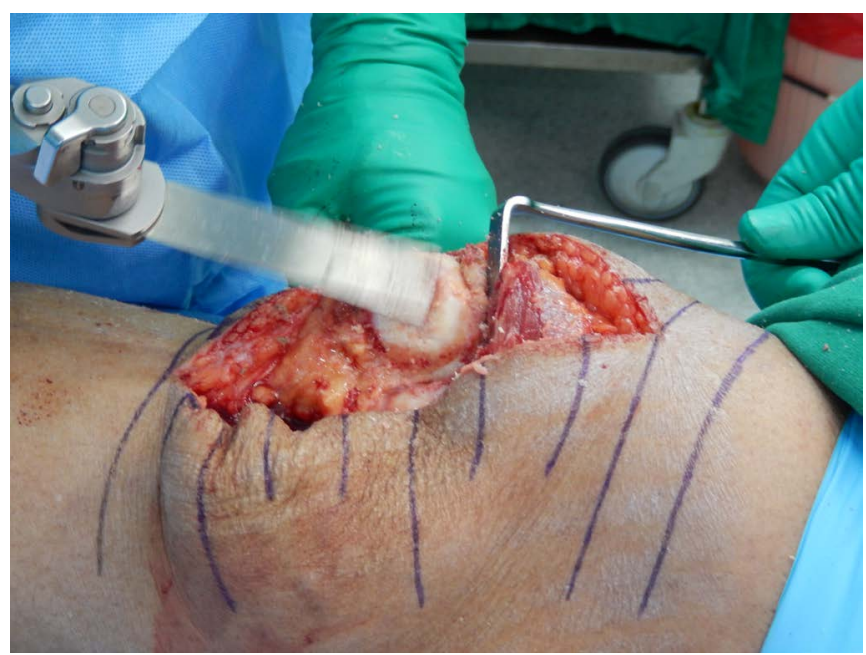

Figure 6. Articular surface of the patella smoothened using a power saw.

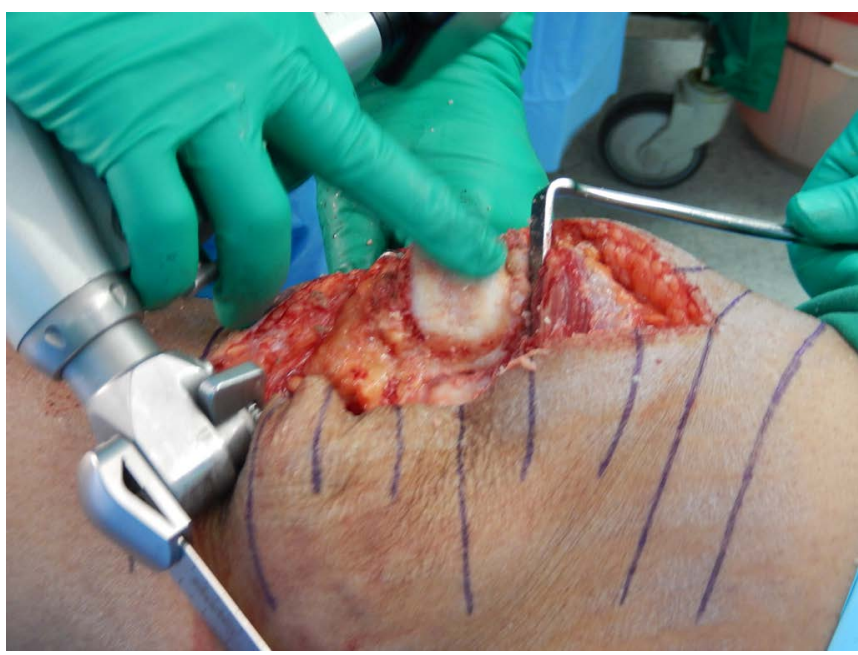

Figure 7. Finesse of the articular surface confirmed by finger. 
an issue of debate since a long time [11]-[16]. There have been substantial studies which have reported that the procedure has improved pain relief and ability to climb stairs [12] [16], and these have led to surgeons resurfacing the patella as a part of total knee arthroplasty. On the other hand, the presence of early and late complications [12] [17] associated with the procedure has renewed an interest in not resurfacing the patella in total knee arthroplasty.

Hasegawa and Ohashi [18] have published long-term clinical results and radiographic change in the nonresurfaced patella after total knee arthroplasty (78 knees followed for mean 12 years) and have reported excellent results in these patients with respect to pain and patellar subluxation. No patient needed revision surgery for patellar problems. Authors [19] performed similar studies where 199 osteoarthrititc knees were treated with total knee replacement using Low Contact Stress (LCS) knee prosthesis and patellaplasty and none of the patients had resurfacing of patella. None of the patients required resurfacing during the follow-up and there were no reports of significant anterior knee pain, dislocation, maltracking or fractured patella.

Cho et al. [20] retrospectively reviewed 43 cases (35 patients) of total knee arthroplasty with patellar retention performed by a single surgeon over seven years with an average follow-up period of 54 months. According to their study, there was neither significant difference in terms of range of motion, and stair climbing ability nor of patellar shift among all three groups. Total knee arthroplasty with patellaplasty provided satisfactory results without significant problems regardless of the preoperative degree of patello-femoral arthritis.

In situations where the patella was not resurfaced, various techniques had been described for patellaplasty. Yercan et al. [10] described partial lateral patellar facetectomy for isolated patellofemoral arthritis over a period of ten years with mean follow-up of 8 years. They concluded that partial lateral facetectomy was relatively simple and effective surgical treatment for middle-aged to elderly active patients with isolated lateral patellofemoral osteoarthritis who wanted to maintain activity level. Other techniques include the use of electrocautery [8] [21], drilling [9] with sharp tipped drill at the proximal or distal side of the patella to decompress the subchondral bone, use of bone nibblers to excise the osteophytes or a combination of any of these described methods.

This report lacks a head to head comparison with a particular technique. It aims to highlight a combination of surgical technique. Our technique, which employs the use of electrocautery to demarcate the patella rim and the use of a power saw to excise the osteophytes, smoothens the articular surface and excise the hypertrophied lateral facet is an easy and reproducible technique which eliminates all complications of patellar resurfacing. It proves to be a suitable alternative to replacement of patella in total knee arthroplasty and also reduces patients' total cost, a definite step forward.

\section{References}

[1] Ranawat, C.S., Flynn, W.F.J., Saddler, S., Hansraj, K.K. and Maynard, M.J. (1993) Long-Term Results of the Total Condylar Knee Arthroplasty. A 15-Year Survivorship Study. Clinical Orthopaedics and Related Research, 286, 94102.

[2] Meneghini, R.M. (2008) Should the Patella Be Resurfaced in Primary Total Knee Arthroplasty? An Evidence-Based Analysis. The Journal of Arthroplasty, 23, 11-14. http://dx.doi.org/10.1016/i.arth.2008.06.009

[3] Smith, S.R., Stuart, P. and Pinder, I.M. (1989) Nonresurfaced Patella in Total Knee Arthroplasty. The Journal of Arthroplasty, 4, S81-S86. http://dx.doi.org/10.1016/S0883-5403(89)80012-9

[4] Shih, H.-N., Shih, L.-Y., Wong, Y.-C. and Hsu, R.W.-W. (2004) Long-Term Changes of the Nonresurfaced Patella after Total Knee Arthroplasty. Journal of Bone \& Joint Surgery, American Volume, 86-A, 935-939.

[5] Waters, T.S. and Bentley, G. (2003) Patellar Resurfacing in Total Knee Arthroplasty. A Prospective, Randomized Study. Journal of Bone \& Joint Surgery, American Volume, 85-A, 212-217.

[6] McAlindon, T.E., Snow, S., Cooper, C. and Dieppe, P.A. (1992) Radiographic Patterns of Osteoarthritis of the Knee Joint in the Community: The Importance of the Patellofemoral Joint. Annals of the Rheumatic Diseases, 51, 844-849. http://dx.doi.org/10.1136/ard.51.7.844

[7] Englund, M. and Lohmander, L.S. (2005) Patellofemoral Osteoarthritis Coexistent with Tibiofemoral Osteoarthritis in a Meniscectomy Population. Annals of the Rheumatic Diseases, 64, 1721-1726. http://dx.doi.org/10.1136/ard.2005.035568

[8] Gupta, S., Augustine, A., Horey, L., Meek, R.M.D., Hullin, M.G. and Mohammed, A. (2010) Electrocautery of the Patellar Rim in Primary Total Knee Replacement: Beneficial or Unnecessary? Journal of Bone \& Joint Surgery, British Volume, 92, 1259-1261. http://dx.doi.org/10.1302/0301-620X.92B9.24467

[9] Erturk, C., Altay, M.A. and Isikan, U.E. (2011) Patelloplasty with Patellar Decompression to Relieve Anterior Knee 
Pain in Total Knee Arthroplasty. Acta Orthopaedica et Traumatologica Turcica, 45, 425-430. http://dx.doi.org/10.3944/AOTT.2011.2590

[10] Yercan, H.S., Ait Si Selmi, T. and Neyret, P. (2005) The Treatment of Patellofemoral Osteoarthritis with Partial Lateral Facetectomy. Clinical Orthopaedics and Related Research, 436, 14-19. http://dx.doi.org/10.1097/00003086-200507000-00004

[11] Abraham, W., Buchanan, J.R., Daubert, H., Greer, R.B. and Keefer, J. (1988) Should the Patella Be Resurfaced in Total Knee Arthroplasty? Efficacy of Patellar Resurfacing. Clinical Orthopaedics and Related Research, 236, 128-134.

[12] Enis, J.E., Gardner, R., Robledo, M.A., Latta, L. and Smith, R. (1990) Comparison of Patellar Resurfacing versus Nonresurfacing in Bilateral Total Knee Arthroplasty. Clinical Orthopaedics and Related Research, 260, 38-42. http://dx.doi.org/10.1097/00003086-199011000-00008

[13] Boyd, A.D.J., Ewald, F.C., Thomas, W.H., Poss, R. and Sledge, C.B. (1993) Long-Term Complications after Total Knee Arthroplasty with or without Resurfacing of the Patella. The Journal of Bone \& Joint Surgery, 75, 674-681.

[14] Kim, B.S., Reitman, R.D., Schai, P.A. and Scott, R.D. (1999) Selective Patellar Nonresurfacing in Total Knee Arthroplasty: 10 Year Results. Clinical Orthopaedics and Related Research, 367, 81-88.

[15] Wood, D.J., Smith, A.J., Collopy, D., White, B., Brankov, B. and Bulsara, M.K. (2002) Patellar Resurfacing in Total Knee Arthroplasty: A Prospective, Randomized Trial. The Journal of Bone \& Joint Surgery, 84-A, 187-193.

[16] Kajino, A., Yoshino, S., Kameyama, S., Kohda, M. and Nagashima, S. (1997) Comparison of the Results of Bilateral Total Knee Arthroplasty with and without Patellar Replacement for Rheumatoid Arthritis: A follow-Up Note. The Journal of Bone \& Joint Surgery, 79, 570-574.

[17] Healy, W.L., Wasilewski, S.A., Takei, R. and Oberlander, M. (1995) Patellofemoral Complications Following Total Knee Arthroplasty: Correlation with Implant Design and Patient Risk Factors. The Journal of Arthroplasty, 10, 197201. http://dx.doi.org/10.1016/S0883-5403(05)80127-5

[18] Hasegawa, M. and Ohashi, T. (2002) Long-Term Clinical Results and Radiographic Changes in the Non-Resurfaced Patella after Total Knee Arthroplasty: 78 Knees Followed for Mean 12 Years. Acta Orthopaedica, 73, 539-545. http://dx.doi.org/10.1080/000164702321022811

[19] Hwang, B.-H., Yang, I.H. and Han, C.D. (2012) Comparison of Patellar Retention versus Resurfacing in LCS MobileBearing Total Knee Arthroplasty. Knee Surgery, Sports Traumatology, Arthroscopy, 20, 524-531. http://dx.doi.org/10.1007/s00167-011-1593-y

[20] Cho, S.H., Chung, U.H., Chun, C.W. and Yune, Y.P. (2002) Total Knee Arthroplasty without Patellar Resurfacing. The Journal of Korean Knee Society, 14, 111-116.

[21] Baliga, S., McNair, C.J., Barnett, K.J., MacLeod, J., Humphry, R.W. and Finlayson, D. (2012) Does Circumpatellar Electrocautery Improve the Outcome after Total Knee Replacement? A Prospective, Randomised, Blinded Controlled Trial. The Journal of Bone \& Joint Surgery, 94, 1228-1233. http://dx.doi.org/10.1302/0301-620X.94B9.27662 